\title{
The Quality of Work-Life and Work Comfort of Librarians During the Covid-19 Pandemic
}

\author{
Endang Fatmawati* \\ Diponegoro University, Semarang, Indonesia
}

Paper type:
Research article
Article info:
Received September 21, 202
Revised November 3, 202
Accepted November 3,2021
Keywords:
- Librarian
- $\quad$ Quvid-19 pandemic
- Library
- Work comfort

\section{Introduction}

Covid-19 has impacted all aspects of life, including libraries, thereby necessitating the closure of face-to-face libraries and increasing the demand for online services to counter the pandemic spread. Meanwhile, the quality of a librarian's work-life is an important aspect that fundamentally affects the ability to continue serving existing online users even during a pandemic. This is important because every library has an interest in the best performance that can be produced by a series of working systems.

Generally, the quality of the librarian's work-life is a key factor for comfort during working, as it ensures conducive behavior and eventually leads to the achievement of the best performance. Hence, the sub-optimal working comfort for librarians at the Faculty of Economics and Business, Diponegoro University Library during the Covid-19 pandemic was the basic reason behind this research. Several factors exist in the working life of a librarian, of which quality is the main prerequisite for good performance. Besides the pandemic, librarians worked every day for approximately eight hours, which mostly resulted in boredom and discomfort in the library. The performance of a library depends on the librarian's productivity. However, the global Covid-19 pandemic outbreak and monotonous routines as a result of the "stay at home" recommendation caused the

\footnotetext{
${ }^{*}$ Corresponding Author.

Email Address: endangfatmawati456@lecturer.undip.ac.id (E. Fatmawati)
} 
unproductivity of librarians due to an uncomfortable and unsupportive work environment.

Convenience while working is the first step for librarians in contributing to excellence, whereas performance is a measure of their success at work. Library performance is defined as the effectiveness of a library's services and the efficiency of the resources allocated and used to provide them. Conversely, the librarian's performance is the level of work achieved by the librarian and influenced by worker comfort, which is greatly affected by the quality of work-life. Hence, organizations are expected to fulfill the employee performance targets set at the beginning of the year, which are arranged based on the main tasks and position of the librarian level of his position. This effort is directed at creating a pleasant working life, which will make the librarian comfortable. The expectation is to provide a stimulus to generate work comfort while working from home and in the office.

Therefore, the practical benefits of this research are to provide information, add insight, and offer a recommendation for other librarians to discover the factors in the quality of work-life that can facilitate their comfort in the office during the Covid-19 pandemic. Also, the results are expected to contribute to enriching the variety of librarian research related to the quality of work-life, specifically during the pandemic. The quality of work-life is very important because the related factors are the main prerequisites for the work comfort of a qualified librarian. This means that this phenomenon plays a very important role in spurring librarians towards working even while overwhelmed with discomfort due to the pandemic. Consequently, the formulation of the problem is "How is the quality of librarian's work-life towards the comfort of working during the Covid-19 pandemic?"

\section{Literature Review}

Several pieces of research related to the quality of work-life have been performed. This includes teachers' quality of work-life (Hong et al., 2012), academic staff (Daud, 2010; Daud et al., 2015), academic field (Nalwade \& Shri. S. R. Nikam, 2013), higher education academics (Bandar et al., 2018), and nursing (Eslamian et al., 2015). Although the librarians' quality of work-life has been investigated (Aziz et al., 2011; Koohbanani et al., 2019), this present research differs due to the method used, the subject, corpus, and the dimensions explored.

Generally, librarians, either implementing the Work from Home (WFH) or Work from Office (WFO) system, require comfortable conditions. The strict health protocols and rules formulated to tackle the Covid-19 pandemic are permanent procedures that must be obeyed. Subsequently, the convenience of working will lead to a sense of satisfaction and optimal performance, which will improve the quality of the librarian's work-life. Although there is an appeal to reduce mobility during the pandemic, the working mechanism must still be regulated. This consequently necessitates the division of work and environment into shifts for librarians who enter the office, ensuring they stay away from crowds, maintain their distance, wear masks, use hand sanitizers, or wash hands with soap under running water.

Many factors, indicators, or dimensions are encompassed in the quality of work-life, which is directly proportional to work productivity. According to Newstrom (2014), the quality of work-life is defined as a way for an organization to recognize its responsibility in developing perfect performance and working conditions. The factors involved include aspects of open communication, a fair reward system, concern for job security, a satisfying career, caring leader, and participation in decision-making. Bandar et al. (2018) revealed that the main factors that influence and contribute to the quality of work-life are communication and relationships with students, a support staff, and other stakeholders. 
Cummings \& Worley (2015) also mentioned a reward system, physical environment, involvement, guarantee of rights, and the need for appreciation and recognition.

Furthermore, Ivancevich \& Konopaske (2012) explained that the quality of work-life is a general concept that refers to several aspects of work experience. This includes factors such as management and supervisory styles, freedom, autonomy to make decisions at work, a satisfactory physical environment and working hours, work safety, and other more meaningful aspects. Porkiani et al. (2011) stated that the dimensions involved are job security, justice, and equality, alongside material salary and benefits, fields and opportunities for skills improvement, and employees' participation in decision-making.

Therefore, the quality of work-life is always related to work and the overall associated environment. This was described by Aziz et al. (2011), who examined the quality of worklife of university librarians in Malaysia by quantitatively analyzing two aspects, namely work and non-work variables. The job variables were job involvement, role conflict, working time, and standard work schedule, while the non-work variables consisted of family involvement and conflict. In addition, Garg \& Singh (2018) mentioned that the presence of a pleasant quality of work-life for library and information science professionals would provide a feeling of satisfaction about their jobs. All kinds of libraries are focused on user satisfaction. For example, Fatmawati (2021) explains that the school library service, is to provide excellent service to students, teachers, and education staff.

Koohbanani et al. (2019) also measured the quality of work-life of librarians in Iranian public libraries and found that the dimensions of organizational social integration constitutionalism and the capacity for human development are at a good level. The dimensions of the environment, the opportunity for continued growth, security, and safe and healthy work were at a moderate level. Finally, the dimensions of fair and adequate payment, the social relevance of work-life, and total living space were weak. According to Cascio (2015), the quality of work-life is the perception of the mental and physical wellbeing of employees in the workplace, meaning that it entails a set of objective conditions and organizational practices. The level of participation, career development, conflict resolution, communication, health, work continuity, safe environment, fair compensation, career management and advancement, arrangement of the work environment, design of job characteristics, and leadership practices are all aspects of this phenomenon.

Meanwhile, good quality of work-life is the key for determining the level of work comfort of librarians. Fatmawati (2014) stated that the quality of librarians' work-life is the foundation of job satisfaction. Consequently, ten factors involved in the quality of work of librarians have been proposed conceptually, namely pride in working in the library, proper compensation, participation in problem-solving, and involvement in decisionmaking. Others are effective communication, safety, security, and work comfort, alongside career development/opportunities for advancement, job characteristics, work environment, leadership, as well as supporting facilities and infrastructure.

There is a close relationship between the quality of working life in the library and the human resource factor, which is the librarian. Meanwhile, efforts to optimize performance during the Covid-19 pandemic show that the work-life parameter is improving. This means that librarians must feel comfortable while working, even in the presence of largescale emergency restrictions on community activities. Therefore, Fatmawati (2008) explained several ways to enhance librarians' comfort in the office, including a focus on work, avoiding routines, seeking new challenges with innovation and creativity, tackling conflicts, and continuous self-development.

Librarians should not have a 'coolie' mentality, by working only when ordered by their leaders, but must be creative, proactive, and innovative. Therefore, theories $\mathrm{X}$ and $\mathrm{Y}$ initiated by McGregor regarding aspects of human behavior in the work environment can be compared to these qualities. On consideration, theory $\mathrm{Y}$ is more appropriate for this 
context, as librarians who comply with these characteristics are assumed to use selfdirection more, have self-control, work sincerely to achieve professional goals, and make physical and mental efforts inherent in their jobs. Hence, librarians can work from the heart without leadership demands or supervision, remain responsible, and perform optimally.

Theory $\mathrm{Y}$ assumes that the librarian is loyal and committed to the library of employment, as such individuals are aware of their duties and responsibilities, also will work independently without orders or supervision from their superiors. A librarian in this context is understood to have a work ethic and the ability to animate the meaning of his job through motivation by a sense of responsibility for his main professional task and function. The goals and benefits of the librarian are understanding the meaning of the work ethic, including exploring the noble meaning of librarianship work, as well as building a nobler work motivation, increasing love for the profession, strengthening the culture of excellence in work, and forming a superior work culture.

Consequently, there are two explanations for the quality of work-life. First, it is viewed as a set of perceptions about a sense of security at work, job satisfaction, and conditions for growth and development. Second, as a set of goals to be achieved through organizational policies, such as safe working conditions, job involvement, career development policies, and fair compensation.

Although the quality of work-life has very varied parameters or indicators, the most important aspect is its adjustment to the conditions in the research location. This variable is exhibited in the job of librarians through their working hours, compensation, and working conditions, as well as the opportunity for career growth and promotions, training, and further research. It also includes communication and complaints, such as between officers and the leadership, and reports to the leadership. According to previous literature, the factors involved in the quality of work-life include pride in working in the library, involvement/participation of librarians, occupational health, job restructuring, security, and enrichment, adequate compensation, democratic supervisor, career development, equitable compensation, wellness, work environment safety, conflict resolution, and communication.

\section{Method}

This research employed a qualitative descriptive approach to understanding the phenomenon of librarians' quality of work-life during the Covid-19 pandemic. It involved exploring the librarian's experiences holistically by describing the research findings. A single cross-sectional design technique was used by measuring an object of research with similar characteristics and information. The informants comprised thirteen librarians with similar job characteristics of working at the Library of the Faculty of Economics and Business, Diponegoro University. Since one agency was used, all kinds of systems and rules concerning the quality of work-life will be similar or uniform.

Meanwhile, descriptive research collects information to describe a variable and a symptom or condition at the time of investigation rather than test certain hypotheses. This research was performed between January to March 2021 and employed interviews as the data collection technique. The interviews were conducted on the thirteen informants by inquiring about the factors affecting the quality of a librarian's work-life. Then, the results were described to visualize the effect of the quality of the working life on the comfort of librarians during the Covid-19 pandemic. 


\section{Results and Discussion}

The results of this research were obtained by processing the collected data, followed by a detailed and in-depth analysis, and finally, formulation of the findings. From the relevant analysis related to the librarians' quality of work-life during the Covid-19 pandemic, the results of the processed and analyzed data can be explained as follows:

\subsection{Characteristics of Informants}

Research by Thakur \& Sharma (2019) revealed that gender, age, hierarchical level, and marital status had no impact on the quality of work-life, while annual income had a significant effect. In this research, the data processing activities were performed by grouping the distribution of the thirteen informants using five parameters, namely gender, age, years of service, educational background, and status. Then, the processed data were grouped based on the characteristics of the informants to define the obtained percentages. The data processing results of the characteristics of the librarians at the Faculty of Economics and Business, Diponegoro University, are shown below:

\subsubsection{Description by Gender}

The distribution of informants by gender showed a greater dominance of male librarians, comprising nine persons with the initials $\mathrm{Yo}, \mathrm{Ad}, \mathrm{Yw}, \mathrm{Hr}, \mathrm{Se}, \mathrm{Gu}, \mathrm{Az}$, Ed, and Ze. Conversely, there were four women, constituting 30.77\% with the initials El, Er, Nl, and En. The division of the work location was the information data processing room for Yo, the Integrated Library for $\mathrm{Ad}, \mathrm{Er}, \mathrm{Nl}$, and $\mathrm{Yw}$, and the circulation room for $\mathrm{Hr}, \mathrm{Se}$, En, Ed. Meanwhile, Gu and El were in the reference room, Az in the corner room of Bank Indonesia, and $\mathrm{Ze}$ in the repository room on the third floor. Further analysis showed that the majority of the male librarians were the heads of households responsible for earning a living. Hence, they assume the main role and responsibility of fulfilling the basic living needs of their families.

\subsubsection{Description by Age} 1.

The results of the distribution of informants by age are shown in the following Figure

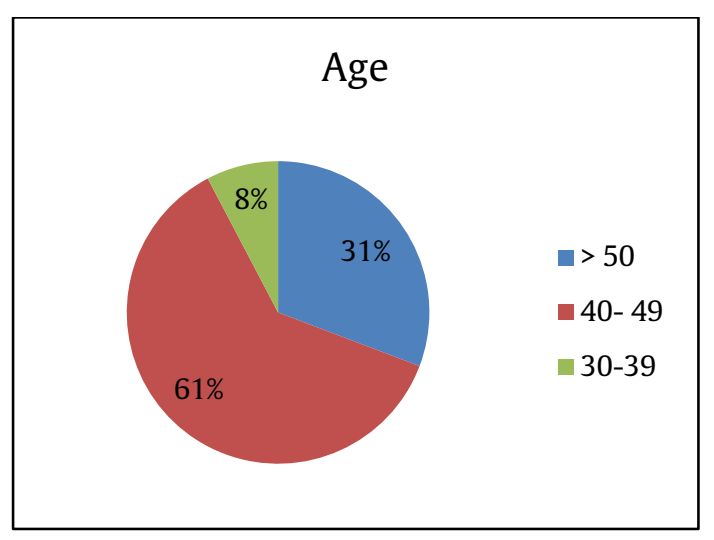

Figure 1. Description by Gender 
Most of the thirteen informants interviewed, particularly $61.54 \%$, were aged between 40 and 49 years. This shows that most of the librarians were of relatively productive ages. The youngest librarian was Ze, aged 36 years old. As an input to the faculty leaders, the librarians approaching retirement age in 2020 can be grouped in the following order, $\mathrm{Gu}$ (57), Se (56), $\mathrm{Er}$ (54), and $\mathrm{El}$ (53). Meanwhile, eight librarians will be aged between 40 and 49 years old in 2021, namely Yo (43), Ad (43), Yw (43), Nl (42), $\mathrm{Hr}$ (44), Az (46), Ed (42), and En (49).

\subsubsection{Description by Working Period}

The results of the distribution of informants according to years of service is shown in the following Figure 2.

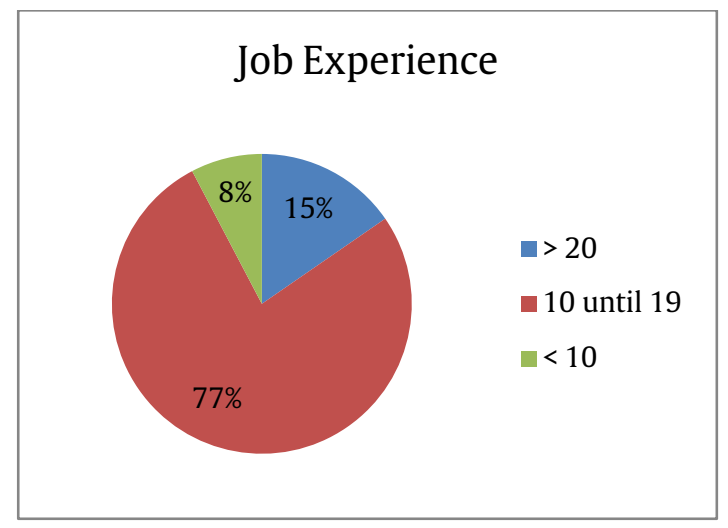

Figure 2. Description by Working Period

The tenure of the thirteen informants was discovered to be very long, at an average of over ten years. An average period of service between 10 and 19 years was the most dominant, showing that the librarians had been working or placed in the library for a long time. This means that a job in the library sector had been ingrained and become the individual's calling. However, a current problem concerns the improvement of the work performed during this pandemic. The reason is very logical, as high quality of work-life during the Covid-19 pandemic will result in increased working comfort and performance.

\subsubsection{Description according to Educational Background}

The results of the distribution of informants in terms of educational background are shown in the following Figure 3. The most dominant educational qualification was high school education or its equivalent, possessed by five persons, which constituted $38.47 \%$ (Er, Ad, Gu, Se, En). This is because most of the librarians initially worked as temporary employees, as the regulations for the appointment of honorary workers to become civil servant candidates previously demanded at least a certain period of service. Conversely, three librarians, particularly $23.07 \%$, had a bachelor's degree in Library Science education $(\mathrm{Nl}, \mathrm{Ed}, \mathrm{Ze})$, showing strong human resources and competence in library science, documentation, and information. There were four informants, at $30.77 \%$, with a nonlibrary bachelor's degree, namely El, Yo, Yw, Az, whereas $\mathrm{Nl}$ and $\mathrm{El}$ had been appointed in the Functional Position of Librarian. Meanwhile, El, being a graduate of another field, was appointed a librarian through the Education and Training of Candidates for Expert Librarians, allowing him to occupy the position of First Librarian. As a report material and 
suggestion to the leadership, the other three librarians with S1 Non-Library education, namely Yw, Az, Yo, can be considered to partake in the education and functional training of librarians in the following year.

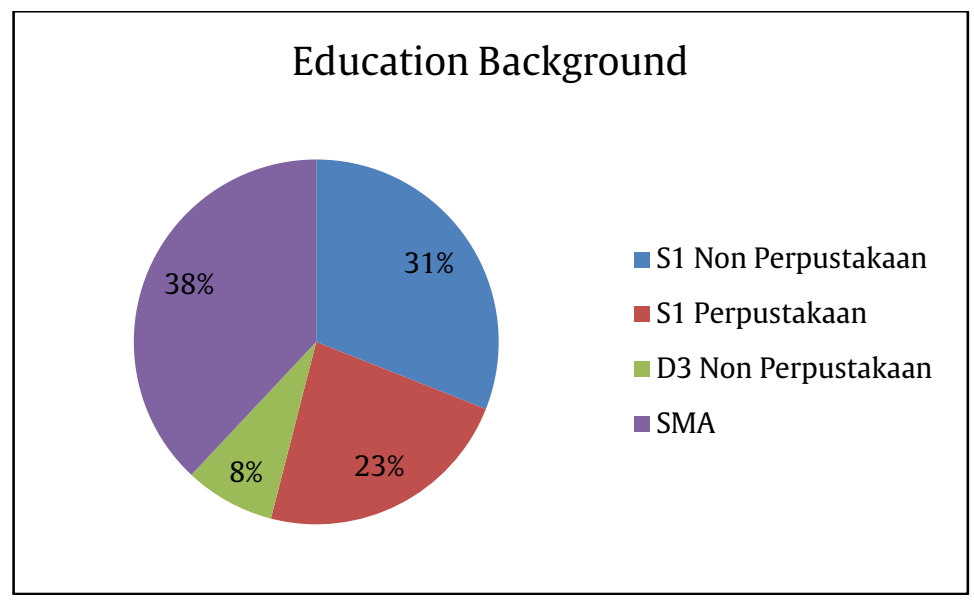

Figure 3. Description according to Educational Background

\subsubsection{Description by Status}

All the informants in this research were married and had families, which served as a motivation to work harder. They were also diligent in working and going to the office to fit their work schedules, meaning their motivation was adequate even during the Covid19 pandemic. This condition was relatively the same at both working atmospheres, specifically the Tembalang campus and Erlangga campus integrated libraries.

\subsection{Formulation of the Research Results}

The quality of work-life is used to explain the working conditions and expectations of librarians, either while working from home or the office during the Covid-19 pandemic. Librarians who consider working in the library fun will create a sense of comfort and a feeling of satisfaction, leading to a better quality of work-life. This quality is related to the quality of life at work while working from home or the office and includes various interrelated areas, such as physical, mental, social, psychological, and economic aspects.

Implementing the quality of work-life for librarians of the Faculty of Economics and Business, Diponegoro University, during the Covid-19 pandemic can increase their productivity and build working relationships that can increase the librarian's attachment to their institutions. Good quality of work-life can create great opportunities for advancement, alongside a conducive work environment. In this discussion, the results of interviews with thirteen informants were presented. This was used to explore the factors or aspects in the quality of the librarian's work-life, while the analysis was related to the comfort of working to improve performance. The results can be explained as follows:

\subsubsection{Financial Compensation}

The fairness of the compensation given affects the quality of working life. In this research, almost all the informants interviewed stated that the provision of compensation 
is the main reason for improved performance. During the Covid-19 pandemic, the obtained compensation was in the form of goods, particularly the provision of nine basic foodstuffs for contract workers. Also, the leadership distributed masks, drinking containers, tumblers, jackets, and food supplements for employees working from the office. According to informant Hr, "It's pretty good to receive food supplements, such as vitamins, eggs, and milk while entering the office during the pandemic."

Professionally, this is a substitute for the contribution of librarians that are already working. The existence of compensation, provided fairly according to the workload, enables the workers to satisfy various needs based on their standard of living. Normatively, the librarian's targets serve as a benchmark to measure their performance.

Meanwhile, some of the informants stated that they received additional performance improvement allowances, mandatory performance incentives, and monthly meals in addition to the civil servant salaries. This is considered to increase librarians' enthusiasm for work during the Covid-19 pandemic, regardless of having to work shifts and perform fingerprint scans while going to and returning work from home. However, others, specifically Se, Gu, Sa, and Az, stated that they occasionally felt lazy after entering the office. The reason was that they felt more comfortable and relaxed working from home, could save gas, and were not required to dress neatly. En and Ad had similar responses, "Actually, without remembering the assignment letter from the leadership, you may be too lazy to come to the office. I just recovered from being exposed to Covid, which still makes me afraid and traumatized."

Informants En and El also revealed that the incentives are subtracted on occasions where the librarian does not work as mandated, such as early closure, late arrival, or absence without explanation. According to the research data analysis, this policy was implemented as a strategic step to instill discipline and as a measure of performance during the pandemic. Although there are individuals who still leave the office during working hours for purposes outside of work, the policy, at least, provides a deterrent effect.

Likewise, the employment status of the informants contributes to the quality of working life. Financial compensation, such as the additional income and incentives provided to librarians, impact work comfort, and as stated by Cascio (2015), the reward system given must be fair, worthy, and adequate.

\subsubsection{Work Environment}

Despite the Covid-19 pandemic, librarians require a conducive work environment, appropriate hours, applicable regulations, and comfortable conditions. The quality of working life in the library will reveal the respect for librarians in their professional environment. During the interviews, eight informants stated that attendance requiring fingerprint scans every morning was stressful. Two informants also revealed that entering at 07.30 and leaving at 16.00 or 17.30 on Fridays was normal. Furthermore, four informants, namely Er, N1, Yw, and Ad, mentioned that the stress of work routines could be managed by going to work on Saturdays during the interview at the Integrated Library of the Airlangga campus.

According to Er, "Whenever I go in on Saturday, Monday becomes an off-day, which I can enjoy by playing at my grandson's place." Such conditions indicate that work routines are allegedly lowering performance because the personnel is bored, though staying and working from home will also cause a sense of saturation. In general, the work environment factors perceived by the informants in the office are good air circulation, adequate lighting, comfortable temperature, strong Wi-Fi, and leadership support. The cleanliness of the 
library room is also maintained because there are special officers, and no noise caused by the photocopier sound.

Another external factor besides the relationship between infrastructure and the clarity of tasks assigned by the leadership is the work environment. The librarian's consideration of work as an obligation and a pile of tasks also leads to saturation. Moreover, working from home offers numerous distractions, such as the problem of computer facilities, disturbance by domestic family affairs, and the crucial issue of the internet network. Therefore, librarians should view the call to work from and stay at home as a form of responsibility and avoid feeling bored. Creative ways to avoid boredom at work involve finding and creating activities, such as fostering a sense of pleasure, an attitude of ease, generating benefits, acquiring new items, and seeking job satisfaction. Also, Luthans (2011) stated the need to pay attention to good conditions such as clean, attractive, and a pleasant environment to facilitate ease at completing work.

\subsubsection{Opportunity to Advance}

During employment, the librarian also requires clarity about his career development in pursuing functional levels. Hence, the social responsibility of the leadership should be ethically accountable according to the staff's competence, such as through providing development opportunities for the librarians. This is consistent with the opinion of Sheel et al. (2012), which stated that the most important determinant of the quality of work-life that provides the best performance is the opportunity for career growth.

This factor is an opportunity to develop the potential of librarians, which is natural because they wish to use their abilities and skills, as well as learn new things. According to an informant in the reference section, the leadership is very responsive in supporting the development of librarians. Informant Er also stated, "Yesterday we had training. I was initially afraid but suddenly got a letter of assignment. Even though the training is online, I am very happy because it adds experience and knowledge and helps me make more friends."

This was agreed upon by informant $\mathrm{Nl}$, who was assigned to attend the event last year, Ad, a participant in the e-office training, and Ze, a partaker of a website integration workshop for a month. Also, Er and Sa felt happy and proud about being ambassadors in an online book review event organized by the Bank Indonesia Library. Informant $\mathrm{Gu}$, who is known to be super difficult when asked to attend seminars or similar scientific meetings, said, "Thank God, I opened my eyes after participating in various webinars yesterday." Likewise, El revealed his delight about being assigned to follow the technical guidance of librarianship, while informants Ed, Az, and Se were assigned to partake in an online catalog integration training, after which they felt enlightened about the slim software that was to be implemented. Therefore, this research analysis concluded that librarians could develop their competencies to become more advanced and professional through this method, even during the pandemic.

Regardless of the presence of the Covid-19 pandemic, librarians must awaken a work ethic while working from home or the office by realizing that their job is a grace, a mandate, a calling, actualization, worship, art, honor, and service. Grace means that the librarian must work sincerely and gratefully. The mandate signifies proper and responsible efforts, while the call indicates the ability to work thoroughly with integrity. Conversely, actualization denotes the librarian must work hard and be full of enthusiasm, while worship means working seriously with love. In addition, art implies performing a job smartly and creatively, honor indicates diligence and excellence, while service means working fully and humbly. 


\subsubsection{Participation in Problem-solving}

The permission to participate or be involved in decision-making to solve problems in the library shows the leadership's recognition of the existence of librarians. Participation is an opportunity to be actively involved in providing and addressing formal and informal input, such as criticism, suggestions, and opinions, to colleagues and the management. This will result in a higher quality of work-life, which correlates with lower work-tofamily interference. Meanwhile, this involvement agrees with the research by Cheung \& Tang (2009) that the quality of work-life concerns the participation of workers in problemsolving and decision-making.

According to the interviews, the librarians are rarely invited to speak and appear to simply accept the existing circumstances. Informant El stated, "Well, we just obeyed and accepted Ma'am for the leadership's disposition and staff rotation without much discussion. You just know it has changed." Good quality of work-life is characterized by providing opportunities for staff to resolve conflicts with leaders in an open, honest, and fair manner. However, librarians may be still considered unrepresentative regarding their suggestions to problem-solving. Meanwhile, the quality of work-life has a role in the course of the main duties, functions, and activities of librarians. This means that the leader must be able to direct and provide opportunities for his subordinates to participate in problem-solving. Hence, Luthans 2011) stated that the quality of work-life emphasizes participation in problem-solving and decision-making.

\subsubsection{Job Characteristics}

The work given by the leadership depends on the competence of each librarian. Meanwhile, job characteristics are very important and fundamental for motivating librarians to improve their performance even during the Covid-19 pandemic. In this research, the division of the job description can be explained as follows. The Reference category, comprising $\mathrm{Gu}$, El, and Ze, the Circulation unit consists of En, Ed, Hr, and Se, as well as information data with Yo. In addition, Az operates in the reading corner of Bank Indonesia, during Er, Ad, Yw, and N1 work in the Integrated Library.

Subsequently, the thirteen informants answered that their competencies and job descriptions matched. There are also special officers, particularly informants Ed and Ze, who handle library websites, publications, and promotions through social media. The general tendency during the interviews with each informant was to state that there was no ambiguity in the roles assigned by the library head, meaning the implemented activities were their respective job descriptions and duties. Hence, the performance of librarians will be improved by the right division of labor according to the characteristics of their work and competencies.

A characteristic that indicates the quality of a librarian's work-life during the Covid-19 pandemic is the feeling of an improvement in following established internal communication through online media, which increases the focus and quality of the job. The existence of coordination, motivation, and capability enhances librarians' loyalty to the library, and creating a good working climate will improve their performance. Therefore, personal work comfort for each librarian is achieved through several means, such as guaranteed welfare. 


\subsubsection{Leadership}

The quality of work-life cannot be delegated unilaterally by the management except through superiors and subordinates. Hence, the leadership factor is very important for the quality of work-life of the staff and must support the jobs of librarians, specifically during the Covid-19 pandemic. Good leaders innovate on different and conducive ways to maintain the quality of work-life and are democratic, thereby ensuring librarians feel valued for their competencies and capabilities.

According to informant Ad, "The leadership is very attentive and has demonstrated their approval of the library staff when they follow online user guidance or training during office hours." Likewise, Er reported that "Even during the Covid-19 pandemic, food allowance and performance incentives are mandatory and the monthly disbursement is smooth, which motivates the spirit of work." Informants En and Se were also cohesive, not because they worked in the same room, but due to the kind and considerate leadership, which often monitors the library even when there are technical problems. Hence, the leading factor explored in this research can be concluded to be very good because it supports the library staff in improving their performance.

Furthermore, good leadership aims to provide a sense of security to subordinates by facilitating staff participation and involvement in decision-making. In this context, it means making appropriate decisions or directly influencing the work of the librarians.

\subsubsection{Pride in the Workplace}

Librarians' jobs are influenced by internal (dispositional) and external (situational) factors. The internal factors include pride in the workplace, education, knowledge, expertise, experience, personality, satisfaction, and work commitment. Every librarian needs to nurture and develop a sense of pride in their workplace, as well as self-respect. The leadership, through the head of the library, is interested in creating an identity that can stimulate a sense of pride, such as the existence of work uniforms.

According to informant Se, "It's nice to be in uniform as it engenders togetherness and a solid work team." The processed data also showed that all informants were proud that there were dress codes and work uniforms. This comprises batik patterns every Friday, yellow clothes with the agency logo for Mondays, and blue on Thursdays. The use of uniforms signifies the cohesiveness of the librarian team in serving the academic community due to their solid, neat, and professional appearance.

Meanwhile, performance generally includes terms of business, loyalty, potential, leadership, and work morale. The performance of a librarian is a result achieved by executing their duties and responsibilities according to the applied job level criteria. It is affected by several indicators, including motivation through promotion in performing their main tasks and functions in the library. Conversely, knowledge consists of knowledge and skills possessed by librarians, which are obtained through formal and non-formal education. Skills refer to the abilities and expertise possessed by librarians, acquired through maturity of experience after receiving education and training.

\subsubsection{Building Effective Communication}

The manifestation of social integration in communication through interpersonal and group relationships is very important. Librarians require a sense of belonging to fulfill social needs. This can be achieved through effective communication, reflected in the conveyance and reception of messages by librarians to their counterparts and the 
leadership or vice versa. Subsequently, the thirteen informants enthusiastically expressed their pleasure in performing community service every fourth Friday, where shelving and cleaning the library space simultaneously builds emotional closeness and effective communication.

According to informants Se and Er, "Usually we were directed by the head of the library and effectively communicated during the Covid-19 pandemic through WhatsApp. Occasionally, we are called." Likewise, informant Se at the Tembalang campus affirmed, "During the pandemic, the circulation team was good and effective at communicating, because they reminded each other and coordinated the services to the students and lecturers. Although the beginning of the pandemic was difficult, this second year was smooth." Therefore, the librarians have been actively communicating with one another and their leaders during the Covid-19 pandemic.

The librarians must develop interactions by communicating effectively with each other as well as the leadership to ensure the completion of tasks through teamwork. This is because the key to work comfort is the ability to build effective communication. Generally, communication is used in various aspects, and recent research showed that its success affects confidence levels. This was discovered by Bell \& Pou (2009), who stated that subjective performance and self-confidence are statistically significant and positively correlated.

Hence, the communication factor is very important and substantive in the implementation of librarians' work. The frequency of meetings at the office reduced, particularly during the Covid-19 pandemic, and all forms of coordination were performed by utilizing technology media, such as WhatsApp, Zoom, and Microsoft Teams. Finally, all librarians were forced to become technology literate and master the use of online media for communication. Although the beginning of the pandemic in March 2020 was difficult and had an unclear mechanism, adapting all systems can work. An informant stated that "During the pandemic, we optimized the WhatsApp Group to communicate with friends. Occasionally, the leadership was invited for coordination meetings via Microsoft Teams, as well as through Zoom." Recent research showed that the success of communication affects the level of confidence, alongside the resulting performance.

\subsubsection{Workplace Safety}

According to informant En and supported by $\mathrm{Hr}$, Se, and $\mathrm{Gu}$, "It is safe because there are library building officers who stand by and guard with a shift system." Informants Yw and Ad also stated that the conditions in the campus library were relatively conducive because of the security officers guarding the area during the Covid-19 pandemic. Under these conditions, the parameters or indicators of workplace safety have been generally guaranteed.

Therefore, the library management is obliged to create, develop, and provide a guarantee of a safe working environment for librarians for achieving a quality of work-life that urges the employees to improve their performance. This was proven to be conducive according to five of the informants interviewed, namely Yo, Ad, En, Hr, and Sa. The other eight librarians also stated that their workplace is safe and free from problems considered to endanger the safety of the employees. This is consistent with the research by Cascio (2015), which stated that work security signifies a feeling of security at work. 


\subsubsection{Working Hours}

The working hours to be fulfilled by the librarian during the Covid-19 period will influence their work comfort. A comfortable working atmosphere mainly consists of a work-from-home system, office shift arrangements, resumption, and half days. Hence, increasing employee job satisfaction and quality of work-life can be achieved by improving the organizational climate. The government, through the Ministry of Empowerment of State Apparatus and Bureaucratic Reform, set the working hours for state civil servants. According to Aziz et al. (2011), work time is an important factor based on the conception that personal resource is scarce, as well as its reduction of the time available for non-work activities.

Subsequently, the thirteen informants stated that working hours during the Covid-19 pandemic became more relaxed because their entries were implemented in morning or afternoon shifts. There was also a maximum alternation of three times a week to enter the office. However, the results of working from home were discovered to be less than optimal compared to full-time at the office. According to informant El, "I usually stay in the office even though I am WFH because I am comfortable. My grandchildren tend to disturb me a lot when I work from home. Also, the computers and collections for processing are in the office." Meanwhile, the working hours, including for the informants, are still being arranged by considering Covid-19 control in the work environment, specifically from the office, thereby necessitating the maintenance of health protocols. Hence, a circular from the Chancellor of Diponegoro University regarding working hours during the pandemic is a reference and implementation guideline for all academics, including librarians.

\section{Conclusion}

Good quality of work-life for librarians during the Covid-19 pandemic is indispensable for the success of the library because it contributes to their convenience and performance improvement. Therefore, the research results were evaluated and refined into conclusions and suggestions to provide input, constructive suggestions, corrections, considerations, and reports to the leadership to improve the performance of librarians. The sectorial strategic results concluded that the convenience of working as a librarian at the Faculty of Economics and Business, Diponegoro University during the Covid-19 period affected the quality of work-life and the resulting performance. Subsequently, this research was conducted using interviews and qualitative descriptive methods, which showed that the ten indicators or parameters of the quality of work-life variable significantly affected the performance of librarians. This comprised various factors, namely financial compensation, work environment, opportunities for advancement, participation in problem-solving, job characteristics, leadership, pride in the workplace, building effective communication, workplace safety, and working hours.

Consequently, several suggestions were made, including increasing the number of librarians holding functional positions, alongside assigning the available resources to participate in technical education and training through online and e-learning methods. Furthermore, building a conducive quality of work-life in the library is required to ensure the librarians are comfortable while executing their jobs and motivated to improve their performance. Finally, the performance of librarians during the Covid-19 pandemic can be optimized by adapting the determination and hard work of the librarians of the Faculty of Economics and Business, Diponegoro University. An understanding of the work ethic in managing information library resources is also related to the quality of work-life variables. 
References

Aziz, R. A., Nadzar, F. M., Husaini, H., Maarof, A., Radzi, S. M., \& Ismail, I. (2011). Quality of work life of librarians in government academic libraries in the Klang Valley, Malaysia. The International Information \& Library Review, 43(3), 149-158. https://doi.org/10.1016/j.iilr.2011.07.002

Bandar, N. F. A., Sabil, S., Jayos, S., Amaran, M. A., \& Hamdan, R. (2018). Quality of Work Life among Academicians in Selected Public Institutions of Higher Learning in Sarawak. Global Business and Management Research, 10(2), 218-222.

Bell, J. N., \& Pou, R. (2009). Performance Intelligence at Work: The 5 Essentials to Achieving The Mind of a Champion (1 ed.). McGraw-Hill Education.

Cascio, W. F. (2015). Managing Human Resources: Productivity Quality of Work Life Profits (10 ed.). McGraw Hill.

Cheung, F. Y.-L., \& Tang, C. S.-K. (2009). Quality of Work Life as a Mediator Between Emotional Labor and Work Family Interference. Journal of Business and Psychology, 24(3), 245-255. https://doi.org/10.1007/s10869-009-9103-7

Cummings, T. G., \& Worley, C. G. (2015). Organization development \& change. In $C T$ Cengage Learning (10 ed.).

Daud, N. (2010). Quality of work life and organizational commitment amongst academic staff: Empirical evidence from Malaysia. ICEMT 2010 - 2010 International Conference on Education and Management Technology, Proceedings, 271-275. https://doi.org/10.1109/ICEMT.2010.5657657

Daud, N., Yaakob, Y., \& Ghazali, S. N. M. (2015). Quality of work life and organizational commitment: Empirical investigation among academic in public institution of higher learning. International Journal of Applied Business and Economic Research, 13(7), 6127-6144.

Eslamian, J., Akbarpoor, A. A., \& Hoseini, S. A. (2015). Quality of work life and its association with workplace violence of the nurses in emergency departments. Iranian journal of nursing and midwifery research, 2011$), 56$.

Fatmawati, E. (2008). STRATEGI PUSTAKAWAN KERASAN DI TEMPAT KERJA. WARTA Jujur dan Mandiri, Media Informasi dan Komunikasi Perpustakaan Nasional RI, 13(3 \& 4), 23-24.

Fatmawati, E. (2021). Layanan Perpustakaan Sekolah: Panduan Bagi Pemula. Deepublish. Fatmawati, E. (2014). KUALITAS KEHIDUPAN KERJA PUSTAKAWAN SEBAGAI FONDASI KEPUASAN BEKERJA. Media Informasi: Forum Komunikasi Perpustakaan, Perpustakaan UGM Yogyakarta, 23(1), 1-10.

Garg, B., \& Singh, S. N. (2018). A Study to Measure the Impact of Quality Work Life on Job Professionals. International Journal of Information Dissemination and Technology, 8(4), 220. https://doi.org/10.5958/2249-5576.2018.00046.8

Hong, K., Tan, K., \& Bujang, S. (2012). Relationships Between Work Life Quality Of Teachers With Work Commitment, Stress And Satisfaction: A Study In Kuching, Sarawak, Malaysia. Jurnal Teknologi, 52(1), 1-15. https://doi.org/10.11113/jt.v52.133

Ivancevich, J. M., \& Konopaske, R. (2012). Human resource management(12 ed.). McGraw-Hill Irwin.

Koohbanani, H. K., Zarei, A., \& Erfani, N. (2019). Measuring the librarians' quality of working life in the Iranian public libraries. Library Management, 408/9), 532-542. https://doi.org/10.1108/LM-11-2018-0089

Luthans, F. (2011). Organizational behavior: an evidence-based approach(12 ed.). McGraw-Hill.

Nalwade, K. M., \& Shri. S. R. Nikam. (2013). Quality of Work Life in Academic: A Review of 
Literature. IJSR - International Journal of Scientific Research, 2(2), 63-65. https://doi.org/10.36106/IJSR

Newstrom, J. W. (2014). Organizational behavior : human behavior at work. McGrawHill.

Porkiani, M., Yadollahi, M., Sardini, Z., \& Ghayoomi, A. (2011). Relationship between the Quality of Work Life and Employees' Aggression. Journal of American Science, 72), 687-706. http://www.jofamericanscience.org/journals/amsci/am0702/75_4889am0702_687_706.pdf

Sheel, S., Goel, S., \& Pathak, S. (2012). Quality of Work Life , Employee Performance and Career Growth Opportunities : a Literature Review. Zenith International Journal of Multidisciplinary Research, 2(2), 291-300.

Thakur, R., \& Sharma, D. (2019). A Study of Impact of Demographic Variables on Quality of Work Life. Productivity, 59(4), 358-365. https://doi.org/10.32381/PROD.2019.59.04.5 